\title{
Audience as Consumers: The Emergence of Media Audience as Gods
}

\author{
AYO-OBIREMI, IfeKristi*, ADELABU, Omowale \\ Redeemers' University, Ede Osun state, Nigeria \\ *Corresponding Author: AYO-OBIREMI, IfeKristi, Redeemers' University, Ede Osun state, Nigeria

\begin{abstract}
Passive media audience has become history as media audiences have progressed beyond information-receivers who are fed with content to active consumers of media content. This progressive change has afforded media consumers the opportunity to dictate the kind of information they want, the time they want it, the manner they want it and the platforms they want to receive it. Media consumers are 'gods' as media owners revere and pay close attention to them so their contents can be selected and they remain in business. They thus embark on audience researches to understand their consumers. This does not make them less powerful but has changed the dynamics of media operations. Studying media audience and their roles as consumers, this qualitative study has explained the emergence of media audience as 'gods' and the evolution of media theories from the Magic Bullet theory in the 1930s to the Cultivation theory propounded in 1976.
\end{abstract}

Key words: Media Audience, Receivers, Consumers, Communication theories, 'gods'

\section{INTRODUCTION}

The media since its inception has experienced diverse changes in content and dissemination over the years. From print content creation for newspapers to audio content for radio to audio/visual for television and a combination of all for digital media; media owners have had to be on their toes to adapt to these changes. Individuals have over time moved from accessing media content on big devices- television, radio to movable devices- smaller radio sets, newspapers and now, hand/mobile devices that has brought information and media content to our personal space. Cohen (2017) says 'we live in a $4+$ screen world where we've got smart phones, tablets, computers, television and e-readers'.

The concept of 'media audience' was not a major focus of research before the advent of the television, radio and now, the internet. With this growth and development, the media has become a part of an individuals' everyday life consciously or subconsciously and a lot of attention has been shifted to media audiences as they play the different roles as consumers, producers, products and so on. Media audience as consumers of content are important parts of the media process.

With these changes have come changes in tenets of mass communication theories that have evolved to accommodate the effects of media content on audiences. This study is limited to the audience as consumers in the media marketplace out of the various roles the audience now play in media processes. This qualitative library research examines media audience as consumers; the emergence of media audience as gods and the evolution of theories that were propounded based on media audience effects.

\section{Media Audience}

Media audience is full of continuities and discontinuities (Livingstone, 2005) but is believed to have emerged when the power of the mass media was dominant and had effects on a 'weak, toothless, isolated and passive' group of people (Oso, in Arowolo, 2017). Moores in D'Antonio (n.d.) refers to the term 'audience' as one who pays attention to or 'gives audience' in a physical/verbal communication process. The idea of 'audience' grew and consisted of groups of individuals who watched live performances/events (Michelle, 2018) and the concept metamorphosed over time to a joint name given to consumers of "electronically mediated messages".

Media audience in an elaborate form refers to one or thousands of people who receive media content by place, people, type of medium, content or time in way(s) intended or not by media producers 
(McQuail in Michelle, 2018; Te Kete Ipurangi, n.d.). With the growth of mass communication and media studies, the audience encompasses heterogenous, anonymous, diverse individuals/groups that receive media content at the exact time of dissemination as intended and others who will stumble on or intentionally delay receiving the content to a later time (fragmented audience). The reception and interpretation of media content by the audience can differ based on background, religion and other individual differences or issues in the environment (Te Kete Ipurangi, n.d.). Victoria Nightingale in D'Antonio (n.d) opines that based on these differences and the problem that individuals are not audiences by nature; media audiences are many times so-referred by culture (context and text-bound) i.e. audiences are so called in specific or particular times and places and not necessarily anytime a media content is disseminated.

The audience is probably the major key stakeholder in the media marketplaceas different arguments have ensued back and forth on if the audience and the media can exist independently or in isolation. Some scholars have noted that the audience has been in existence before the emergence of the media and thus, the media is not complete without them. A few others like Tony Bennett in D'Antonio (n.d.) opines that the audience exists because of the media. In his opinion, "the audience did not exist at the emergence of modern media but developed as a product of the media practices". There is however no definite conclusion to this argument but the media and the audience work hand in hand for the mediaaudience process to be complete.

Being part of a media audience indicates a consumer/recipient role rather than a producer-initiator role. Traditionally, audience members were regarded as passive participants who receive information and process without questioning. With technological advancement and societal growth; there has been a tremendous change in who the audience really is. They are no longer dependent media receivers who take and digest all the media puts in their faces. They are now independent, active and interactive thinkers who make sense of media messages (D’Antonio, n.d; Ayo-Obiremi\&Adelabu, 2020).

As changes occur in who the media audience is and their roles, there is an increased need for audience analysis, segmentation and analysis as efforts are being put into research to know who media audiences are, what they read/listen to or watch and various reasons for their actions. Results from these findings help media owners improve content and in turn, produce happier, satisfied consumers.

\subsection{Types of Media Audience}

Cullum (2011) and Stevenson (2014) identify two major types of audience- the mass audience (individuals who consume popular content targeted at large groups of people) and niche audience (a unique-interest group of people who are small in number but very influential e.g. special-interest media or professional media channels). The audience could also be classified based on their psychographic or demographic characteristics.

\subsection{Audience as Consumers}

The idea of 'consumer' stems from the business/marketing/advertising world where individuals are end-users of products as consumption is being studied in many areas of research. Consumers are the main reason media houses and business people are still in existence. A business or media house cannot exist effectively if there is no one to receive and digest all the hard work put into achieving content.

The incorporation of advertising into media studies, the demand for media as a 'highly consumeroriented good' and the evolution of media language brought the concept of media audience as "consumers". Scholars like Andrew Wernick in Puustinen (2006) says advertising communication has spread to the other forms of communication and he calls it "commercialisation" or "promotional culture". The 'audience' as stated above are passive and active receivers of media content but with the evolution; media audience do not just receive content but consume these contents thus making media content 'products' to be sold to consumer audiences (Puustinen, 2006).

Media consumers have access to information everywhere and anywhere with personal and handhold devices like mobile phones, personal computers and other electronic devices. Their consumption of content differs based on their age, gender, social class, culture and other demographic andpsychographic variables (Cohen, 2019). In the United States, statistics show that in 2017, the average US adult (18+) spent about 12 hours with the media per day with the most time on digital media (5hours 50 minutes); television (4 hours 4 minutes) and their desktop/laptop, mobile devices, 
radio print and other connected devices between 21 minutes and 3 hours per day (Cohen, 2017). These figures have shot up since then as more time is spent daily with the media. In Africa, more youths than others spend time consuming media content as Africa has the highest population of youth in the world (Wangari, 2017). The trend in media consumption in Africa is similar to the United States as the number of hours spent consuming media content has risen over the years. Statistics for African countries however show the increasing rate of digital media consumption and not the general media consumption figures. Broadband Search (2020) notes that an average of 3 hours and 10 minutes is spent consuming social media content and this is the highest of all the other media. This statistic is less than the average number of hours the average US adult spends on digital media daily. Nonetheless, the trend in media content consumption is similar and has risen drastically over the years.

In the media marketplace, the media is the "torchbearer to the interest of common man" (Singh \& Singh, 2009) and thus, creates content that is sold and/or given to the audience and they become the consumers. Daily and as time permits, media owners/content creators make content available to reach the audience that will consume the content. These contents/products offered to the consumers include news, programmes, films, advertisements (products and services), web pages, articles, etc (Zayim, n.d). The audience in turnsearches for thecontents that serve their needs and consume them for various reasons- satisfaction, information, entertainment, instrumental value, social interaction, aesthetics, suspense, surprise, humour, etc (Hasebrink, 2011). Consumption habits have changed over the years with digital advancement. Content is consumed ondifferent levels of attention. Cohen (2017) identifies 5 content consumption types which are: focused consumption where the consumer fully concentrates on media content on one device; dual consumption where the attention and content consumption is divided between 2 or more devices simultaneously; information snacking where content is consumed instead of wasting time; time shifted content where content consumption is postponed till later and content binging where multiple portions of content is consumed in a single session.

Dodkins (2010) opines that not all consumers can be satisfied on the same level as some engage in preferred reading where the audience consumes the content as intended; some others aberrant reading where the audience rejects the content and negotiated reading where the media content is interpreted to suite the consumer and not as intended by the sender.

Webster \& Phalen (1997) in Napoli (2015) notes that some media managers see media consumption as a two-stage process of making a decision to consume content via a particular medium and the second stage making a specific decision between individual content options. Napoli (2015) opines that media owners seek opportunities to make revenue from their consumers thus, sell media content to the audience. However, these consumers have enjoyed 'free' content over time from various media sources (legal or illegal) and are not willing to pay for content. Thus, media owners seek ways to balance providing content to their audience and generating enough revenue to sustain their media houses.

In a bid to balance content provision and revenue, media owners across the world make certain media content free but place a certain amount on other content that is of interest to their consumers. This system has become increasingly possible with the internet and e-commerce- media content can be packaged, sold and feedback will be gotten (Zayim, n.d). The efforts of media owners are however sometimes thwarted by the circulation of pirated copies of the 'withheld' content (Napoli, 2015).

Ultimately, the success and effectiveness of media products is determined by audience response and thus, the consumers of the media products- the audience, have a say in the kind of media developed. To satisfy media consumers, meet media audience demands and ensure effectiveness of media content, media owners should consider the following as listed by Dodkins (2010) - audience engagement, audience expectations, foreknowledge, identification, placement and research.

\subsection{The Concept of 'gods'}

The concept of 'gods' in everyday life is peculiar to different religions and cultures. It is the belief in a supernatural being that controls nature and guide human lives. These gods are believed to have the final say over fate and destiny. gods dictate the essence of human existence, what to expect and what to live for. With gods, human lives are subject to what is believed to be their decisions/opinions and are more often than not, unquestionable. In ancient Greek, a few of their most important gods that 
controlled different things are Zeus (the god in charge of the rain and sky); Hera (goddess of marriage/childbirth); Poseidon (godof the sea); Aphrodite (the goddess of love); Hades (the god of the underworld) and Ares (the god of war/battle) (Greek Mythology, 2009).

Puustinen (2006) notes that the audience as consumers can be viewed from various economic and social structures but these consumers have power and their personal opinions to act within the structures of economy and culture. Webster in Arowolo (2017) opines that viewing these consumers from various perspectives can be categorised into micro and macro views. The former gathers information on the internal motivation of consumers and what drives them from within to consume certain content as opposed to some others. The latter views the consumers from 'outside' as their characteristics and behaviours will be examined.

\section{Media Consumers ANd Mass COMmunication TheORIES}

The emergence of media audience and consumers as gods can be attributed to the changes in audience participation and media content consumption. As media consumption evolved, so did theories on media effects on its audiences(media audience theories) and the narratives changed quickly as consumers began to set the tone for content creators. When media consumers consumed media mainly for information and receiving content without negotiation, theories sprang up that explained the powerful effects of media messages/content on media audience. The major one is the magic bullet/hypodermic needle/transmission-belttheory propounded by Harold Lasswell in the 1930s. This theory assumes that media audiences do not have a say in receiving and interpreting content disseminated as information was received and acted upon as intended by media owners without questions or objections. The media audiences in this theory were passive, helpless receivers of information who could not decipher the right or wrong of media messages. This theory was questioned by Lazarsfeld, Berelson and Gaudet in the 1940's when they conducted a study on elections and 'The People's Choice'. Their findings led to the introduction of Limited/Minimal Effects Theories of the media on their audience. The first in these is the two-step flow theory where media audiences were influenced by interpersonal relationships like opinion leaders whose comments their voting choices more than the media did. (Nwabueze\& Okonkwo, 2018).Similar to the two-step flow theory is the multi-step flowtheory by Katz and Lazarsfeld propounded in 1955. They opine that like the theory above, media content/messages flow from the media to its audience through multisteps/stages (Anaeto, Onabajo\&Osifeso, 2008)

Later on, in1957, Leo Festinger presented another theory in which media audience had a greater say in how media content affected him or her. The Cognitive Dissonance Theory assumes that when an individual is exposed to logically incompatible information, the person experiences psychological discomfort and tries to reduce dissonance and achieve consonance. Thus, the person changes attitude, behaviour and modifies perceived importance of such attitude. A step beyond this theory is the Perception Theory propounded in 1964 by Berelson and Steiner which assumes media consumers perceive information in a complex form as individuals selectively expose, pay attention to, perceive and retain media content based on their pre-existing notions, ideas and beliefs. Media consumers do not agree with media content that do not support their pre-existing beliefs and thus, do not pay attention to or remember such content when the need arises. By 1970, Melvin De Fleur propounded the Individual Differences Theory that assumes media audiences are made up of different people with diverse backgrounds, psychological characteristics and experiences. All of these combines to affect attitudes, beliefs and values and thus, affect their perception of media content.

Consumers had started to take control of media content based on the assumptions of the theories from the Magic Bullet Theory up to the Individual Differences Theory. A major twist in the evolution of these theories in favour of media consumers arose in 1972 when Maxwell Mc-Combs and Donald Shaw propounded the Agenda-Setting theory which assumes that the mass media does not always determine what the audience thinks but gives them what to think about. This is achieved by repeating content in certain ways, using captions, headlines and points that will make certain content the major subject of consumers' discussions. This theory does not put the consumer in full control of content as the media drives the way content will flow to the audience. This then brings questions on the accuracy of previous theories that have supported media consumers as controllers of media content they receive and interpret. About a year after, the Spiral of Silence theory was propounded by Noelle-Neumann and this theory supports the consumers' ability to think and react to media content. However, the individuals' perception, conclusions and reactions to the messages are influenced by public opinion 
and they feel pressured to conceal their opinions when they believe they are in the minority (Anaeto, Onabajo\&Osifeso, 2008). The postulations of this theory do not in any way stop media consumers from selecting media content and reacting to them as long as they do not share their views publicly.

Theories that support media consumers as 'gods' over media content and their selection of the content went a step beyond the Individual Differences Theory as the Uses and Gratifications Theorywas postulated by Elihu Kalz, Jay Blumbler and Michael Guveritch in 1974. This theory further explained the power of the audience in controlling media content and their consumption patterns. This theory portrays the audience as 'gods' in control of what they consume as they select content that will satisfy their diverse needs of relaxation, knowledge, social interaction, entertainment etc. Audience crave satisfaction and/or gratification for their needs as Abraham Maslow classified these needs into 5 basic and 2 additional segments- physiological, safety, love/belonging, esteem, self-actualization, understanding and aesthetic needs (Aruma\&Hanachor, 2017). By 1976, Gerbner, Gross, Morgan and Signorielli propounded the Cultivation Theory that assumes that although people select what to consume and perceive the content based on what they believe; constant and repeated exposure to certain media content can distort their perception of reality. The tenets of this theory were mainly for television effects on media audience but can be related to every other medium (Anaeto, Onabajo\&Osifeso, 2008). Over time, scholars realised that media consumers became major stakeholders in media content and they receive and interpret content different based on mood, background, previous experiences, intention, trust, circumstances and habits (Scott \& Dietz, 2016).

Some scholars have opined that despite the great assumptions of the Magic Bullet Theory that was instrumental in the history of communications research, the changes in audience roles has led to its obsolescence over time. However, Nwabueze and Okonkwo (2018) in a study conducted on the Monkey Pox Killer Vaccine Incident of October 2017 and Salt Water Bath incident of August 2014 concluded that the magic bullet theory and its powerful effects on media audience should not be completely discarded. Based on their findings, media consumers can actively select which media platform to be exposed to but depending on the issue, they passively react to contents they are exposed to. This brings back the effectiveness of the early theory in a modern world.

These constant changes in media consumers and their consumption habits have been attributed to certain factors identified by McQuail (2010) in Arowolo (2017) and Merdler (2020). The factors include multiplication of media channels which has led to overload of content and reduced attention span; increase in audience size due to emerging conglomerates; mass audience fragmentation; market characteristic segmentation; interactive/consultative audiences and the escape of the audience from management and measurement.

Irrespective of the ups and downs in the different theories on the effects of media content on the audience, the changes in content delivery and a consumer-oriented media places emphasis on what people do with the media and not what the media can do. The audience as 'gods' are active media users and no longer slaves to media content (Katz in Arowolo, 2017) and thus, shape media content. The audience have at their advantage a degree of freedom to select the content they wish to consume and when they wish to be exposed to and consume such content.

To satisfy these 'gods' and remain in business, Cohen (2017) advices that media content be converted into different formats (texts, visuals, video, audio etc) based on consumption types/habits and multiple distribution platforms can be used. This advice is in tandem with Statista report in Watson (2020) on the time Americans spend consuming digital media versus traditional media content. Time spent consuming digital media content rose from 214 minutes in 2011 to 403 minutes in 2019 and the time spent consuming traditional media content (radio, television and newspaper) declined from 453 minutes in 2011 to 348 minutes in 2019. This trend as reported up to 2018 is the same in Argentina, Canada, Indonesia, United Kingdom, Columbia, Egypt and South Africa (Global Web Index, 2019). This shows the move in consumption trend from traditional to digital media. Media owners that want o keep being relevant has to know this and adjust to fit the changes in society.

As media audience has grown to the status of 'consumers' who are to be satisfied, media owners have to understand and know everything possible about these consumers to satisfy their needs and wants. Media owners have to deliver content in the way their consumers will want it, the format they prefer, time of the day and the device they prefer (Cohen, 2019). Delivering the right content in the right way to media consumers takes a lot of time and research efforts. There should be a proper comprehension 
of what constitutes 'news' to the consumer and their various tastes, preferences, listening, reading or viewing time.

Media content creators should then research changes in media consumption from time to time and reasons for changes and then research the complexities and peculiarities of the consumers and their consumption habits (Scott \& Dietz, 2016). 'The media is still very powerful and influential today but its influence is more complex than in the early days of Mass Communication' (Communication Studies in Nwabueze\& Okonkwo, 2018).

\section{CONCLuSion}

Media audiences over the years have evolved from passive receivers of information to active receivers and participants of media content. This progression has earned them the title 'consumers' who receive content and consume for various reasons- satisfaction, entertainment, social interaction, education etc. The evolution from 'audience' to 'consumers' can be attributed to various factors like background, exposure, emerging conglomerates, audience fragmentation and advancement in technology among other factors.

As consumers, the audience dictates what they want to consume, how they want it and on specific platforms depending on their backgrounds, individual differences and pre-existing beliefs and values. Theories like the magic bullet theory has been used to explain the powerful effect of media content on the audience and how the media passed information to passive receivers. Other theories have sprung up stating the limited effects of media content on their consumers but did not completely eliminate the assumptions of the initial theory that birthed the subsequent media research theories. The different theories from the two-step flow theory to the cultivation theory propounded in different years explain how consumers are exposed to media content and factors that distinguish their various reactions to these contents.

As 'gods', media owners revere the audience and go extra miles to understand changes in consumption patterns, reasons consumers select certain content and platforms above others and other factors that make consumers appreciate media content as products. This does not eliminate the effectiveness or supreme power of the media to influence its consumers but it reflects the need to understand the consumers and satisfy them.

\section{REFERENCES}

[1] Anaeto, S., Onabajo, O. \&Osifeso, J. (2008). Models and Theories of Communication. USA: African Renaissance Books Incorporated.

[2] Arowolo, S. (2017). Media Audience: The Unending Swing of the Pendulum. https://www.researchgate. net/publication/320978021_Media_Audience_The_Unending_Swing_of_the_PendulumRetrieved June, 2020.

[3] Aruma, E. \&Hanachor, M. (2017). Abraham Maslow's Hierarchy of Needs and Assessment of Needs in Community Development. International Journal of Development and Economic Sustainability. Vol. 5 (7): $15-27$.

[4] Ayo-Obiremi, I. \&Adelabu, O. (2020) Internet and Changing Audience Role in News Processes. Research Journal of Mass Communication and Information Technology. Vol. 6 (2): 24-36

[5] Broadband Search (2020). Average Time Spent Daily on Social Media (Latest 2020 Data). https://www. broadbandsearch.net/blog/average-daily-time-on-social-media Retrieved June, 2020.

[6] Cohen, H. (2017). How we Consumer Content Now (And what it Means for Your Marketing. Actionable Marketing Guide. https://heidicohen.com/infographic-how-we-consume-content-now-what-it-means-foryour-marketing/ Retrieved June, 2020.

[7] Cohen, H. (2019). Audience Media Consumption Data: How to Improve Your Marketing. Actionable Marketing Guide. https://heidicohen.com/audience-media-consumption-data/ Retrieved June, 2020.

[8] Cullum, S. (2018). Audiences. Media Audiences: An Introduction. https://www.slideshare.net/alevelmedia /media-audiences-an-introduction Retrieved June, 2018.

[9] D’Antonio, E. (n.d.). Audience. The Chicago School of Media Theory. https://lucian.uchicago.edu/blogs/ mediatheory/keywords/audience/ Retrieved June, 2020.

[10] Dodkins, C. (2010). Understanding Audiences and Target Audiences. Education. https://www.slideshare. net/guest14c40ed3/understanding-audiences-and-target- audiences-3537792 Retrieved June, 2020

[11] Global Web Index (2019). Digital vs Traditional Media Consumption. Trend Report 2019. https://www.a mic.media/media/files/file_352_2142.pdf Retrieved June, 2020 
[12] Greek Mythology (2009). Greek Mythology: The Olympians. History Editors. https://www.history.com/ topics/ancient-history/greek-mythologyRetrieved June, 2020

[13] Hasebrink, U. (2011). Giving the Audience A Voice: The Role of Research in Making Media Regulation More Responsive to the Needs of the Audience. Journal of Information Policy. Vol. 1:321-336

[14] Livingstone, S. (2003). The changing nature of audiences: from the mass audience to the interactive media user [online]. London: LSE Research Online. http://eprints.lse.ac.uk/archive/00000417 Retrieved June, 2020.

[15] Livingstone, S. (2005). Introduction to the special issue 'Audience and Publics' [online]. Retrieved from LSE Research Online: http://eprints.lse.ac.uk/archive/00000436 Merdler, S. (2020). How Content Consumption and Creation is Changing (and how to keep up). Publishing Executive. https://www.pubex ec.com/article/how-content-consumption-creation-is-changing-and-how-to-keep-up/ Retrieved June, 2020.

[16] Michelle (2018). Mass Media Audience. Communication Studies. https://michellemathiasfsp.blogspot.co m/2018/10/mass-media-audience.html Retrieved June, 2020.

[17] Napoli, P. (2015). The Audience as Product, Consumer and Producer in the Contemporary Media Mar ketplace. DOI: 0.1007/978-3-319-08515-9_15

[18] Nwabueze, C. \& Okonkwo, E. (2018). Rethinking the Bullet Theory in the Digital Age. International Journal of Media, Journalism and Mass Communication. Vol. 4(2): 1-10. DOI: 10.20431/2454-9479.04 02001

[19] Puustinen, L. (2006). The Age of Consumer-Audience: Conceptualising Reception in Media Studies, Mar keting and Media Organisations. Department of Communication, University of Helsinki. http://c iteseerx.ist.psu.edu/viewdoc/download?doi=10.1.1.455.3216\&rep=rep1\&type=pdf Retrieved June, 2020.

[20] Scott, M. \& Dietz, C. (2016). The Significance of Audience Research in Media Development. Media Dev Akademie. https://www.dw.com/en/the-significance-of-audience-research- in-media-development/a19556460 Retrieved June, 2020.

[21] Sing, A. \& Singh, M. (2009). Media Audience: The Prospective Consumer. Scribd. https://www.scribd.co m/document/13888204/Media-Audience-Prospective-consumer\#Retrieved June, 2020.

[22] Stevenson, A. (2014). Why is Audience Important to Media Producers? Prezi Videos. https://prezi.com /hbg6ldu6ospi/why-is-audience-important-to-media-producers/Retrieved June, 2020

[23] Te Kete Ipurangi (n.d). Audience. Ministry of Education, New Zealand Government. https://mediastudies.tki.org.nz/Teaching-media-studies/Mediaconcepts/Audience\#: :text=A\%20media\%20audience\% 20may\%20bewith\%20the\%20products\%20they\%20consume.Retrieved June, 2020.

[24] Watson, A. (2020). Time Spent with Digital Versus Traditional Media in the US 2011-2020. Statista. https://www.statista.com/statistics/565628/time-spent-digital-traditional- media-usa/RetrievedJune, 2020.

[25] Zayim, M. (n.d.). As Role of Audience or Consumer in the New Media. Academia.edu. Retrieved June, 2020

\section{AUTHOR'S BIOGRAPHY}

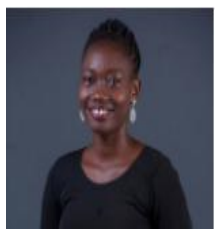

AYO-OBIREMI, IfeKristi is a student, graduate assistant and researcher in the Mass Communication field. Her major interests are Media studies, Advertising and Public Relations.

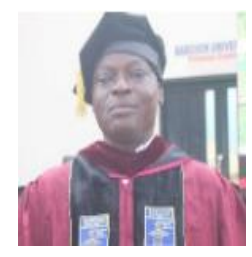

ADELABU, Omowale $(\mathrm{PhD})$ is a Mass Communication scholar and Senior

Lecturer in the Department of Communication and Media Studies,

Redeemers' University, Ede, Osun State. His interests are in Mass

Communication related subjects but he specialises in Media Studies,

Journalism and Marketing Communication.

Citation: AYO-OBIREMI, IfeKristi, ADELABU, Omowale. "Audience as Consumers: The Emergence of Media Audience as Gods" International Journal of Humanities Social Sciences and Education (IJHSSE), vol 7, no. 7, 2020, pp. 85-91. doi: http://dx.doi.org/10.20431/2349-0381.0707010.

Copyright: (C) 2020 Authors. This is an open-access article distributed under the terms of the Creative Commons Attribution License, which permits unrestricted use, distribution, and reproduction in any medium, provided the original author and source are credited. 